\title{
Principles and the Understanding of Service Innovation in Design Education
}

\author{
Ahmad Zuhairi Abdul Majid \\ Product Design, School of The Arts, Universiti Sains Malaysia, Penang \\ zuhairi.majid@usm.my
}

\begin{abstract}
In the rapid development of technology, South East Asia countries always have the opportunity to experience new products and services. New design ideas, principles and methods for service innovation and design will change designers' value in education and creative industries that are suitable for the next generation. The understanding of service innovation with its principles for future generation will merge with the understanding of experience economy that can build the service environment to be more sustainable. The new generation is looking for personal satisfaction with emotional value to their lives. This topic will give an opportunity for designers to play their role in helping the industry efficiently with quality concept of service businesses in this region. This paper is an academic discourse focused on service innovation and design with some examples on the important elements and analyses for the development of a service.
\end{abstract}

Keyword: Design Service, technology, innovation education

\section{INTRODUCTION}

Innovation is usually defined as the creation of novelty that provides economic value to the creation of new products and services. Service innovation is a new term in 21 st century that was proposed in 2004 at the United State Council on Competitiveness. The reason was because the role of service sector has become so important in our modern society. It is a trend to improve our lifestyle and the industry by using scientific research and techniques systematically with service innovation idea. With service innovation, a provider will have a better service quality, loyal customers, new experience and sustainable in terms of benefit, profit and social development responsibility. According to Pine and Gilmore (2011) previously there were economic shifts such as the Industrial Economy and the Service Economy since two centuries ago. These shifts are failed to bring the progression of economic value to higher-echelon offerings. They stated that today we have new economy offering which is the 'Experiences Economy'. Service economy is when a person purchases a set of intangible activities carried out on his or her behalf. But, when a person buys experience, one pays to spend time enjoying a series of memorable events that a company stages some presentations to engage the user in a personal way. Two things to be noted here are selling services or selling experiences. Both are from service business category.

\section{LITERATURE REVIEW}

There are five factors for achieving quality service according to Berry \& Parasuraman (1991), they are reliability, tangibles, responsiveness, assurance, and empathy. In contrary, Hollins (2006) says that customer contacts, quality, storability, tangibility and transportability are the main factor in achieving quality service. On the other hand, Lin (2008) had an idea of putting things on a quality service with more effective way with Five Fs; fun, function, feelings, fancy and friendly are important in developing a service today.

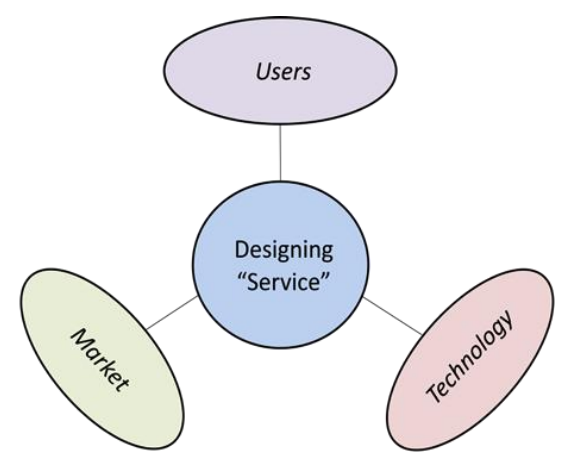

Figure 1. Basic service innovation and design structure.

The designers play big role to educate users by creating a good concept especially on the environment surrounding within one service premises successful concept. The history can tell us that there was an evolution of service businesses even from seventies until now. Previously service businesses always carry the word efficient service with customer satisfaction. Today, the trend is 
much related to the technology that available for quality rather than only efficiency for customer conveniences. In this study, the authors shall establish principles and methods so that a new strategy in designing a service in Malaysia can be succeed. We also realized that the basic service structure as in figure 1 consist of technology, market and user that will effectively support in designing a service. Service innovation is also considered as a new area in design discipline. One of its reasons is the first international conference on service innovation and design in Asia was initiated. It is called the "International Conference of Service Innovation Design", that was held at Dongseo University, South Korea in 2008.

Lockwood (2008) claimed that service design has emerged as a human-centered approach that focuses on the customer experience and the quality of service encountered as the key values of success (as cited in Maiden, 2010). The touchpoints experience on the web or experience with the reception counter has the similarity, especially on the human interaction aspect. Ojasalo (2009) discussed that competitions and the rapid pace of structural changes in the economy creates the emerging of service innovation and development as a strategic imperative for most companies. Designers from many disciplines such as industrial designers, interior designers or even landscape architects possibly will contribute to the development of service businesses such as presales, after sales, transportation, foods, health care, tourism, financial, entertainment, education and many other services. Service innovation design is now becoming necessary to the current information society. This is due to rapid changing of new technologies that had been applied to new products and services development. Before creating the application and content, the designers should look into conceptual thinking or the strategic design thinking that will lead to a novel kind of creation for service businesses. Moreover, shifting to the industrial revolution 4.0, with we are now competing with the internet of things and automation working culture. Creating the applications and contents for service businesses are so challenging. Designers have to make sure the consumers or customers can easily understand by considering the human factors and interaction issues for their satisfaction and of course to achieve customer loyalty. Some issues can be adapted from manufacturing service systems which now looking at industrial big data. Big data is a term that usually refer to predictive analytics or user behaviour analytics. There are issues highlighted by Lee, et al. (2014) that in order to improve overall performance and maintenance in big data environment, we must tackle fundamental issues like managers and operator interaction, product and process quality, big data and cloud or sensor and controller network. There are sections that must be done by engineers and software developers. This cocreation is a must to put things together in the development of a service.

Service design is a profession concerned with improving the experience that customers receive from a service provider. Service design can be both tangible and intangible, involving artefacts and other things including communication, environment, and behaviours. Consistency, easy to use and strategically must be applied in order to winning the customers (Hollins, 2006). The word 'design' is commonly used as a noun or a verb. As a verb, it refers to a plan for the construction of an object or a system. Traditionally, the understanding of the word 'design' is of 'a plan or drawing produced to show the look and function or workings of a building, garment or other object before it is built or made (Oxford, 2008). Design also is the thought process comprising the creation of an entity (Miller, 2004). The researcher admires his thought that design is the mental synapse that instantly sees the potential connection between problem and possibility. Another suggestion is that when design involves, decisions must be made in respect of colour, styling, durability, reliability, materials, cost of manufacture and so on (Mudie \& Pirrie, 2006). While 'service' combines with the word 'design' it means a process that creates an offering to the recipients. As we all know that IBM had started dealing with Service Science and exchange of information to develop a curriculum in cooperation with 35 universities in the United States (Dickson \& Ford, 2010). Behind this background IBM promotes Service Science following the old success experience of establishing Computer Sciences. But most of all 42 subjects were not related to service at the first introduction of service science curriculum at University California, Berkeley (Ono, et al, 2008). They were more related knowledge and techniques of management for manufacturing industry that can be adapted for services sector. 


\section{PRINCIPLES AND PROCESSES}

A principle had been established that which we agreed upon the five basic principles of service design thinking. User-centred, co-creative, sequencing, evidencing and holistic are the main principles to be followed as were discussed by Stickdorn \& Schnieder (2011). Service design is a system for visualizing, enabling services to be given proper position and weight in the market entity (Shostack, 1981). It has been agreed for decades that innovation can play a role in the development of service industries (Barras, 1986).

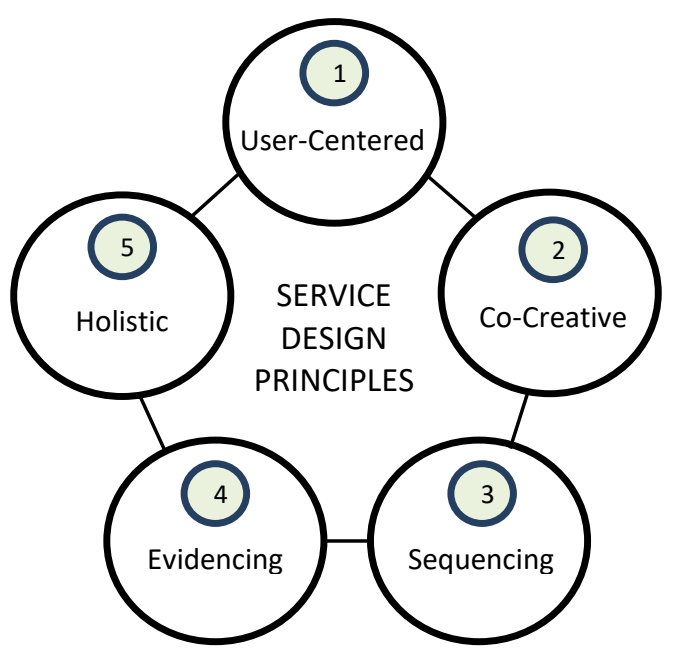

Figure 2. The 5 principles of Service Design Thinking discussed by Stickdorn and Schnieder (2011).

Below are some of the important the rationales of the principles according to Stickdorn et al. (2018):User-Centered - A service should be experienced through the customer's eyes with a certain degree of necessary participation. It is essential to obtain statistics of customers description, a true understanding of habits, behaviours, culture, social context and motivation of users.

Co-Creative - The involvement of all stakeholders in the design process. In order to come up with ideas of how to design a new service or to improve an existing service, a consideration of getting people from front-line, back-office employees, managers, as well as the non-human interfaces such as vending machines or application software to be part of the development process.

Sequencing - Service timeline is crucial. The sequence of service moments should be well organized or planned by laying out all the steps in a blueprint diagram. The interaction could be human to human, human to machine or machine to machine, but also occur indirectly via third parties, such as reviews from other customers via print or online media. Service moments not only consists of what is happening front of stage, it also includes multiple backstage processes that can't be seen by customers.

Evidencing - Intangible service should be visualized in terms of physical artefacts. It is an acknowledgement of intangibility of a service offering, and of how we can draw attention to the value created by a service. Servicescape is another term used to address all tangible artefacts involved in a service.

Holistic - The entire environment of a service should be considered. The intention should always be to see the wider context in which a service process takes place. There should be a focus on alternative customer journeys such as alternative touchpoints and approaches. Both level of customer and service provider must look into various perspectives to ensure a great customer experience.

\section{Example of Sequencing in a Blueprint}

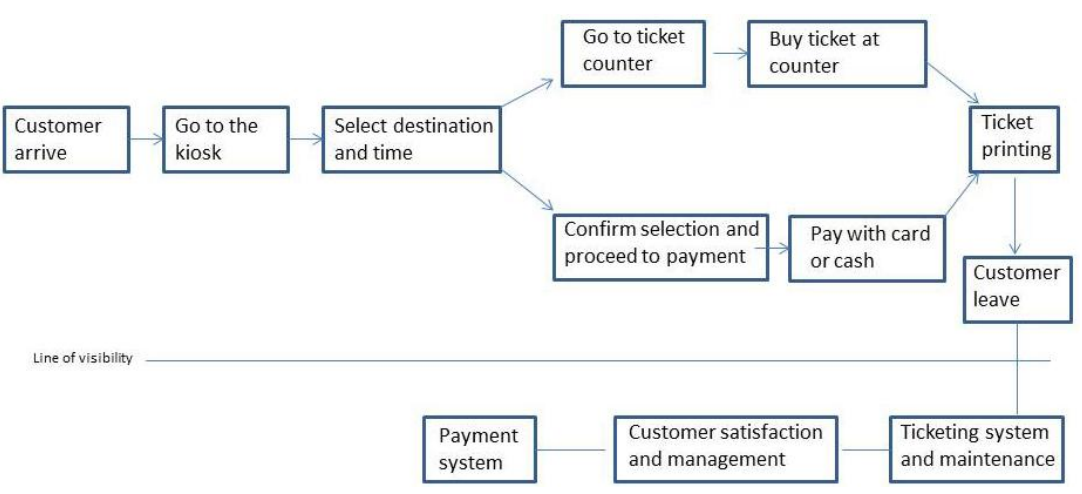

Figure 3. Blueprints of the sequencing while purchasing tickets. 
Figure 2 shows the flow of the proposed service blueprint for express bus ticketing system at bus terminal in Penang. The student proposed new steps to be taken and this also shows how the situation will be experienced by the users when purchasing tickets. Users will go through simple process of interaction from a ticketing machine. This will increase users' level of satisfaction.

Table 1. One example of assessment on the project proposed by students.

Assessment Category

Level of Importance

Explanation of Rating

1. Quality of

user interfaces

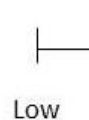

Low

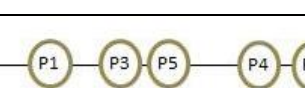

Medium

P6 has user friendly interfaces that understandable. The quality of interfaces is essential. The other projects can be considered as moderate usage of interfaces.

Table 1 is an example of the assessment to service innovation project. This assessment was adapted from the assessment of industrial design's role by Ulrich \& Eppinger (2000). Some parts were altered to suit with the service design thinking principles. From the assessment above we can see that not all projects done by the students can achieve higher rating, but the most important was the contribution to the knowledge and practice of service design thinking. P1 to P6 are the numbers represent projects to be assessed. The author thinks that the students have gained important knowledge and they are ready to take part in a bigger role of service design practice. This method of assessment is related to the service design thinking principles. Below are the explanations of each criterion to be used in the assessment.

1. Quality of user interfaces - The first principle is about user-centred that a service should be experienced through the customer's eyes. The rating is to see how easy the product to be used such as the quality of appearance, feel, and mode of interaction.

2. Emotional appeal - This rating is very much related to user-centred and evidencing. Servicescape that involves in any service can be visualised and appeal is achieved through appearance, feel, sound and smell. A question like how attractive is the service or how exciting about the service will be the first probe by the users or customers.

3. Maintenance ability - In order to keep service quality at the highest value, service providers must have maintenance plan which is not concern by the customers but can be seen during delivery. Holistic thinking for the entire environment includes before and after delivery. Although it is intangible but in a physical environment that uses physical products to deliver.

4. Service differentiation - To be competitive in providing a service, a provider must show their uniqueness and consistency with the identity. New ideas and new way of delivery shows the difference and it is predominantly from appearance. Blue Ocean Strategy can be adapted to create a market for something that did not exist before (Kim \& Mauborgne, 2005).

5. Effective Sequencing - This rating related to the principle and it should be visualized as a sequence of interrelated actions. Although dynamic processes will take place but the service timeline is crucial because users cannot wait too long if it is slow delivery. Every service design or innovation must provide a blueprint that represent as an effective sequencing.

\section{DISCUSSION AND CONCLUSION}

This study could spark the interest of many educators in design discipline at higher education institutes such colleges and universities. Although it will conflict with the existing curriculum in service marketing in most business schools but the researcher feels that this of has a lot differences in terms of design with innovative ideas through its 
processes. As the researcher mentioned earlier, service innovation is about "creativity" and "service". Contributions will likely be:

- To give preliminary knowledge in service design and development as a new stream for industrial design, graphic design, new media design or any other design related discipline.

- To create opportunities for other researchers to improve the processes and strategies particularly in creative innovation aspect.

- To create new way of linking education and industry by providing expertise in service design and development.

Service design and innovation education will continue on creating new ideas of providing services while focussing on the tangible artefacts that support the service. Not to ignore the term 'emotion' which means how much emotional value will receive by the customers during their visit at any service centre or business. As an example, good ambience music can give good emotional value to customers. A service provider should look at new lifestyle to be added in new development or improvement and the effectiveness is higher when a service provider includes new trends of lifestyle contents (Majid, 2012). According to Esslinger, (2009) "Money buys, but emotional sells". To make this happen, designers must be able to create things that can have a positive effect on the customers' emotional relationship with service functions. New business paradigms are promoting livelier, lovelier, and more emotionally fulfilling products (Lockwood, 2008). The author believe that the word 'products' must always come along with 'services' especially in design management.

\section{REFERENCES}

Barras, R. (1986). Towards a Theory of Innovation in Services. Research Policy 15, 161-173

Berry, L. L., \& Parasuraman, A. (1991). Marketing services. New York: Free Press.

Dickson, D. R., \& Ford, R. C. (2010). Founding a Science of Service: A Discussion with IBM's Jim Spohrer. Journal of Applied Management and Entrepreneurship Vol. 15, 94-110.

Esslinger, H. (2009). A Fine Line: How design strategies are shaping the future of business. San Francisco: John Wiley \& Sons.

Hollins, B. (2006, November 24). Service Design "What is Service Design?” Retrieved January12, 2009, from Design Counsil: http://ww.designcouncil.org.uk/en/AboutDesign/Design-Disciplines/
Kim, W. C., \& Mauborgne, R. (2005). The Blue Ocean Strategy. Boston: Harvard Business School Press.

Lee, J. Kao, H.A. \& Yang, S. (2014) "Service Innovation and Smart Analytics for Industry 4.0 and Big Data Environment". Procedia CIRP 16.

Lin, R. (2008). Service Innovation Design for Cultural and Creative Industries. International Service Innovation Design Conference (pp. 14-25). Seoul: Dongseo University

Lockwood, T. (2008). Design Value: A Framework for Measurement. In T. Lockwood, \& T. Walton, Building Design Strategy (pp. 3-12). New York: Allworth Press.

Lockwood, T. (2008). Design Value: A Framework for Measurement. In T. Lockwood, \& T. Walton, Building Design Strategy (pp. 3-12). New York: Allworth Press.

Maiden, N. (2010) Service Design: It's All in the Brand. IEEE Software, IEEE Computer Society, 18-19.

Majid, A. Z. (2012, October 20-24). Validation on proposals for strategic service innovation at automobile service center. ISIDC2012 (pp. 151-158). Tainan: National Cheng Kung University, Taiwan.

Miller, W. R. (2004). Landscape Architecture Education \& Virtual Learning. Environments Landscape Architecture Online. Heidelberg: Wichmann.

Mudie, P., \& Pirrie, A. (2006). Service Marketing Management, Third edition. London: Elsevier Ltd.

Ojasalo, K. (2009) Business and Design Competences in Service Innovation and Development. The Business Review, Cambridge, Vol. 13, 216222.

Ono, K., Levy, P., Ishizuka, A., Hachima, S., \& Watanabe, M. (2008). Development of Competences for Service Design. International Conference of Service Innovation Design, 411416.

Oxford Dictionary of English. (2008). Oxford: Oxford University Press.

Pine, B. J., \& Gilmore, J. H. (1999). The Experience Economy. Boston: Harvard Business School Press.

Shostack, L. G. (1981). How to Design a Service. European Journal of Marketing Vol 16, 49-63.

Stickdorn, M. \& Schnieder, J. (2011) Service Design Thinking. New Jersey: John Wiley \& Sons, Inc.

Stickdorn, M. \& Schnieder, J. (2011) Service Design Thinking. New Jersey: John Wiley \& Sons, Inc.

Stickdorn, M., Hormess, M., Lawrence, A. \& Schneider, J. (2018) "This Is Service Doing", Sebastopol USA: O’Reilly Media. 